\title{
A pandemia da COVID-19 na saúde da criança: Uma revisão integrativa
}

\author{
The COVID-19 pandemic in children's health: An integrative review \\ La pandemia del COVID-19 en la salud infantil: Una revisión integradora
}

Recebido: 02/06/2021 | Revisado: 14/06/2021 | Aceito: 17/06/2021 | Publicado: 02/07/2021

Lais Dias Berbet

ORCID: https://orcid.org/0000-0001-7491-2633 Universidade Federal de Alfenas, Brasil E-mail: lais.berbert@hotmail.com

Patrícia Scotini Freitas

ORCID: https://orcid.org/0000-0002-8270-8955 Universidade Federal de Alfenas, Brasil E-mail: patricia.freitas@unifal-mg.edu.br

Rogerio Silva Lima

ORCID: https://orcid.org/0000-0002-1751-2913 Universidade Federal de Alfenas, Brasil E-mail: rogerio.lima@unifal-mg.edu.br

Denis da Silva Moreira

ORCID: https://orcid.org/0000-0002-5055-5210 Universidade Federal de Alfenas, Brasil E-mail: denis.moreira@unifal-mg.edu.br

Adriana Olimpia Barbosa Felipe ORCID: https://orcid.org/0000-0002-4491-5750 Universidade Federal de Alfenas, Brasil E-mail: adriana.felipe@ unifal-mg.edu.br

Cristiane Aparecida Silveira-Monteiro ORCID: https://orcid.org/0000-0002-8427-7220 Universidade Federal de Alfenas, Brasil

E-mail: cristiane.monteiro@unifal-mg.edu.br

\begin{abstract}
Resumo
Objetivo: analisar as evidências disponíveis na literatura sobre os principais resultados da pandemia da COVID-19 na saúde da criança. Método: revisão integrativa da literatura realizada de janeiro a abril de 2021 por meio da busca de estudos publicados em 2020 em periódicos indexados no PubMed/MEDLINE, LILACS e Web of Sciense. Resultados: a amostra foi composta por dez estudos primários, publicados em 2020 principalmente em inglês e realizados na Espanha e China. Os artigos que compuseram a amostra do estudo formam sistematizados e apresentados a partir das perspectivas da Saúde Mental, Física e Social. Conclusão: Problemas em sua saúde física e mental, envolvendo mudanças de comportamento, da ansiedade, da obesidade e do sedentarismo. Torna indispensável a criação de estratégias para o retorno ao mundo pós pandemia da COVID-19.
\end{abstract}

Palavras-chave: Criança; Saúde da criança; Infecções por coronavírus; Revisão.

\begin{abstract}
Objective: to analyze the evidence available in the literature on the main results of the COVID-19 pandemic on child health. Method: integrative review conducted from January to April 2021 through the search for studies published in 2020 in journals indexed in PubMed/MEDLINE, LILACS and Web of Sciense. Results: the sample consisted of ten primary studies, published in 2020 mainly in English and carried out in Spain and China. The articles that made up the study sample were systematized and presented from the perspectives of Mental, Physical and Social Health. Conclusion: Problems in your physical and mental health, involving changes in behavior, anxiety, obesity and sedentary lifestyle. It makes the creation of strategies for COVID-19's return to the post-pandemic world indispensable.
\end{abstract}

Keywords: Child; Child health; Coronavirus infections; Revision.

\section{Resumen}

Objetivo: analizar la evidencia disponible en la literatura sobre los principales resultados de la pandemia COVID-19 en salud infantil. Método: revisión integradora realizada de enero a abril de 2021 mediante la búsqueda de estudios publicados en 2020 en revistas indexadas en PubMed / MEDLINE, LILACS y Web of Sciense. Resultados: la muestra estuvo formada por diez estudios primarios, publicados en 2020 principalmente en inglés y realizados en España y China. Los artículos que conformaron la muestra de estudio fueron sistematizados y presentados desde las perspectivas de Salud Mental, Física y Social. Conclusión: Problemas en su salud física y mental, que involucran 
cambios de comportamiento, ansiedad, obesidad y sedentarismo. Hace indispensable la creación de estrategias para el regreso de COVID-19 al mundo pospandémico.

Palabras clave: Niño; Salud del niño; Infecciones por coronavirus; Revisión.

\section{Introdução}

O ano de 2020 ficou marcado como o início da grave crise mundial com a pandemia em decorrência da infecção pelo novo coronavírus denominado Severe Acute Respiratory Syndrome Coronavirus 2 (SARS-CoV-2, em português, Síndrome Respiratória Aguda Grave 2), que provoca a Coronavirus Disease 2019 (COVID-19). Primeiramente detectado na China em dezembro de 2019, espalhou-se mundialmente e foi declarado à nível de Pandemia pela Organização Mundial de Saúde (OMS) em 11 de março de 2020 (World Health Organization, 2020).

Para o enfrentamento da pandemia adotou-se como medida não-farmacológica o distanciamento e o isolamento social, sendo essas estratégias de controle da disseminação da contaminação na população pelo distanciamento físico e redução da mobilidade (Linhares \& Enumo, 2020).

Segundo a OMS, a maioria das pessoas que são infectadas com o vírus apresentam problemas respiratórios. Idosos e pessoas com doenças respiratórias crônicas, cardiovasculares, diabetes, hipertensão e câncer são mais propensas ao agravamento do quadro pela COVID-19 (World Health Organization, 2020). Já as crianças manifestam fisicamente sintomas mais leves, um melhor prognóstico e menor letalidade. Em contrapartida, podem apresentar resultados negativos relacionados a mudanças no cotidiano e no seu bem-estar físico e emocional (Avila et al., 2020).

O distanciamento social gerou, de forma inédita e urgente, uma reorganização do espaço e do tempo, cotidianos das crianças e de suas famílias, uma vez que, as instituições de ensino suspenderam suas atividades presenciais. A indústria, o comércio e os serviços em geral instalaram ou intensificaram o delivery e o home office (Guizzo, Marcello, \& Müller, 2020).

Essas alterações de rotinas e de reorganização do espaço e do tempo poderão ter impactos negativos apresentados em diferentes níveis: nas relações internacionais ou particulares, no desenvolvimento do país, do estado, da comunidade do sistema familiar e individual (Bezerra, Silva, Soares, \& Silva, 2020; Goodman \& Borio, 2020; Guizzo et al., 2020; Linhares \& Enumo, 2020; Miranda, Athanasio, Oliveira, \& Simoes-e-Silva, 2020; Qiu et al., 2020).

Os temores sobre a pandemia, a sobrecarga de tarefas domésticas, a intensa convivência familiar, o desemprego, a diminuição da renda e as incertezas diante da realidade que se impõe podem gerar ou agravar conflitos que já ocorriam em muitos lares, sendo crianças, adolescentes, idosos e pessoas com deficiências os mais vulneráveis nessa relação. Escolas e centros comunitários não protegem mais como costumavam fazer nestas circunstâncias porque encontram-se fechados (Fiocruz, 2020).

Considerando o ambiente estressor da COVID-19 há três grupos de ambientes de risco: a infecção viral pelo SarsCov-2, os meios de controle de sintomas via fármacos antivirais e os efeitos diretos e indiretos do confinamento social diante da experiência coletiva da pandemia (Vigo et al., 2020).

$\mathrm{Na}$ infância, os efeitos diretos relacionam-se às manifestações clínicas da COVID-19, enquanto os indiretos podem impactar o processo ensino aprendizagem, a socialização e o desenvolvimento, além do afastamento do convívio familiar ampliado, com amigos e com toda rede de apoio. Toda essa situação pode agravar as vulnerabilidades e o estresse tóxico, aumentando sintomas de depressão e ansiedade, além da violência contra a criança e consequentemente a diminuição da procura pelo atendimento aos serviços de proteção (Fiocruz, 2020).

A pandemia da COVID-19 trouxe novas preocupações sobre o bem-estar das crianças, principalmente das famílias que vivem na pobreza, o que contribui para o surgimento de outros fatores de risco. O que torna essas crianças mais vulneráveis durante a pandemia em decorrência das dificuldades financeiras e do estresse imposto aos pais, bem como por seu acesso limitado a serviços e sistemas de apoio (Herrenkohl, Scott, Higgins, Klika, Lonne, 2021). 
O fechamento das escolas devido ao isolamento social, embora tenha sido necessário para a contenção da contaminação pelo vírus, gerou mudanças desfavoráveis nos comportamentos referentes a saúde das crianças. O comportamento sedentário, o aumento do tempo de tela, do tempo de sono e consumo de alimentos não saudáveis contribuíram para o ganho de peso corporal, uma vez que a escola é cenário da interação social, da aprendizagem e da prática direta e indireta de exercícios físicos (Bergmann et al., 2020; Silva et al., 2020). Para crianças com problemas de saúde mental, esse fato pode ser ainda potencialmente destruidor devido a ausência de apoio adicional que a escola exercita para a mesma (Tso $e t$ al., 2020).

Deste modo, o presente estudo tem o objetivo de analisar as evidências disponíveis na literatura sobre os principais impactos da pandemia da COVID-19 na saúde da criança.

\section{Metodologia}

Definiu-se como método a Revisão Integrativa (RI) de literatura que tem como objetivo agrupar e sintetizar os estudos realizados sobre determinado tema, para estabelecer conclusões a partir dos resultados, chegar a uma definição ou solução do problema levantado (Polit \& Beck, 2018).

Para este estudo, foi seguida a proposta delimitada por Mendes, Silveira e Galvão (2008) que inclui seis etapas de elaboração da revisão integrativa: definição da pergunta norteadora, estabelecimento de critérios de inclusão e exclusão com a busca na literatura, definição das informações a serem extraídas, avaliação dos estudos incluídos, interpretação dos resultados e síntese dos dados.

A construção da questão de pesquisa foi feita pelo formato PICOT, proposto por Melnyk e Fineout-Overholt (2019), o qual a letra $\mathrm{P}$ refere-se à população de interesse, I é a intervenção ou questão/área de interesse, $\mathrm{C}$ é comparação ou grupo, $\mathrm{O}$ é o resultado de interesse e T é o período para a intervenção ou problema atingir o resultado esperado. As perguntas que utilizam a estratégia PICOT resultam em uma pesquisa eficaz que produz as informações mais relevantes e economiza grande quantidade de tempo para sintetizar a melhor evidência dos estudos existentes na literatura.

A população refere-se as crianças na faixa etária de 2 até 12 anos (P); a área de interesse, a saúde das crianças (I), não houve grupo comparação (C), o desfecho refere-se aos impactos de natureza física, mental e comportamental na saúde da criança (O) e no período da pandemia da COVID-19 (T). Elaborou-se a seguinte pergunta da investigação: "Quais as evidências disponíveis na literatura sobre os principais impactos da pandemia da COVID-19 na saúde da criança?”.

Para a busca dos estudos primários, a internet foi utilizada para acessar as seguintes bases de dados: Medical Literature Analyses and Retrieval System Online (MEDLINE) via PubMed, Latin American and Caribbean Health Science Literature Database (LILACS) e Web of Science (WOS). Os descritores controlados (Medical Subject Headings-MeSH e Descritores em Ciências da Saúde-DeCS) foram respectivamente: criança, saúde da criança e infecções por coronavírus, child, child health e covid-19. Para conduzir a estratégia de busca, foram utilizados descritores que refletiam a questão de pesquisa, com o operador booleano AND. Importante destacar quantos achados foram encontrados por casa base.

Após completar a busca por dois revisores independentes, todos os artigos foram exportados para o EndNote Web Basic (Clarivate Analytics®) e os artigos duplicados foram removidos. Os critérios de elegibilidade foram estabelecidos com base na questão de revisão. Assim, foram incluídos estudos primários que abordaram resultados na saúde da criança (2 a 12 anos) durante a pandemia da COVID-19; publicados em português, espanhol e inglês durante o ano de 2020. Tal ano foi escolhido por ser o ano declarado como pandemia pela OMS, bem como ter sido o ano em que a maioria dos países implantaram medidas gerais contra o COVID-19 como o isolamento (World Health Organization, 2020). 
Os critérios de exclusão adotados foram: Publicações como editoriais, revisões de literatura, resumos de conferências e capítulos de livros, cartas ao editor, comentários e similares. Estudos que avaliaram as manifestações clínicas e complicações da doença, recém-nascidos, lactentes ou adolescentes e estudos em que houve apenas a participação dos pais.

A critério de inclusão, nos estudos cujas investigações continham participação de pais e crianças, incluiu-se apenas informações das crianças.

A coleta e análise de dados do presente estudo foram realizadas entre janeiro e abril de 2021. Para gerenciamento dos resultados foi utilizado o EndNote, para exclusão dos artigos duplicados, posteriormente o programa Rayyan QCRI ${ }^{\circ}$ para seleção dos textos (Ouzzani, Hammady, Fedorowicz, \& Elmagarmid, 2016). Este aplicativo otimiza o trabalho das revisões de literatura, o qual identifica o título, o resumo e a data de publicação dos textos carregados das bases de dados para posterior análise. Assim, permite a inclusão ou a exclusão de cada texto, com possibilidade de incluir a justificativa, o que deixa a filtragem dos artigos mais organizada.

Após a etapa de levantamento das publicações, realizou-se a leitura do título e do resumo das 51 publicações pelas duas revisoras, de forma independente, considerando os critérios de inclusão e exclusão definidos. Em seguida, foi realizada a leitura na íntegra das publicações, atentando-se novamente aos critérios de inclusão e exclusão. Essa etapa auxiliou na categorização das informações extraídas das publicações.

O instrumento, elaborado com a finalidade de extrair e analisar os dados dos estudos incluídos, é composto dos seguintes itens: (1) Autor, (2) Periódico (3) Idioma e país; (4) Tipo de estudo; (5) Objetivo; (6) Principais resultados; (7) Conclusão e (8) Nível de evidência (Melnyk \& Fineout-Overholt, 2019). As etapas de extração e análise dos resultados dos estudos primários foram realizadas por dois revisores, que desenvolveram este trabalho de forma independente.

À classificação hierárquica das evidências é realizada em níveis. Nesse sentido, quanto mais alta a evidência estiver representada na pirâmide, maior será o impacto desta intervenção no efeito de saúde desejado (Melnyk \& Fineout-Overholt, 2019).

Para discussão dos dados, utilizou-se como referencial, as dimensões de saúde da definição da OMS: "saúde é um estado de completo bem-estar físico, mental e social e não apenas a mera ausência de doença ou enfermidade" (OMS, 2008). Ainda que essa definição seja irreal, ultrapassada e unilateral (Segre \& Ferraz, 1997), as categorias físico, mental e social foram adotadas pela diversidade de categorização encontrada na literatura analisada.

\section{Resultados}

A sistematização da seleção das publicações nas bases da literatura científica está apresentada em um fluxograma, com a descrição das etapas de busca com o quantitativo de publicações em cada uma das bases. Foram considerados os critérios de inclusão e exclusão das 2245 publicações, até chegar ao número final de 51 publicações selecionadas para a revisão. 
Figura 1 - Fluxograma do processo de seleção das publicações selecionadas para a Revisão Integrativa. Alfenas-MG, Brasil (2021).

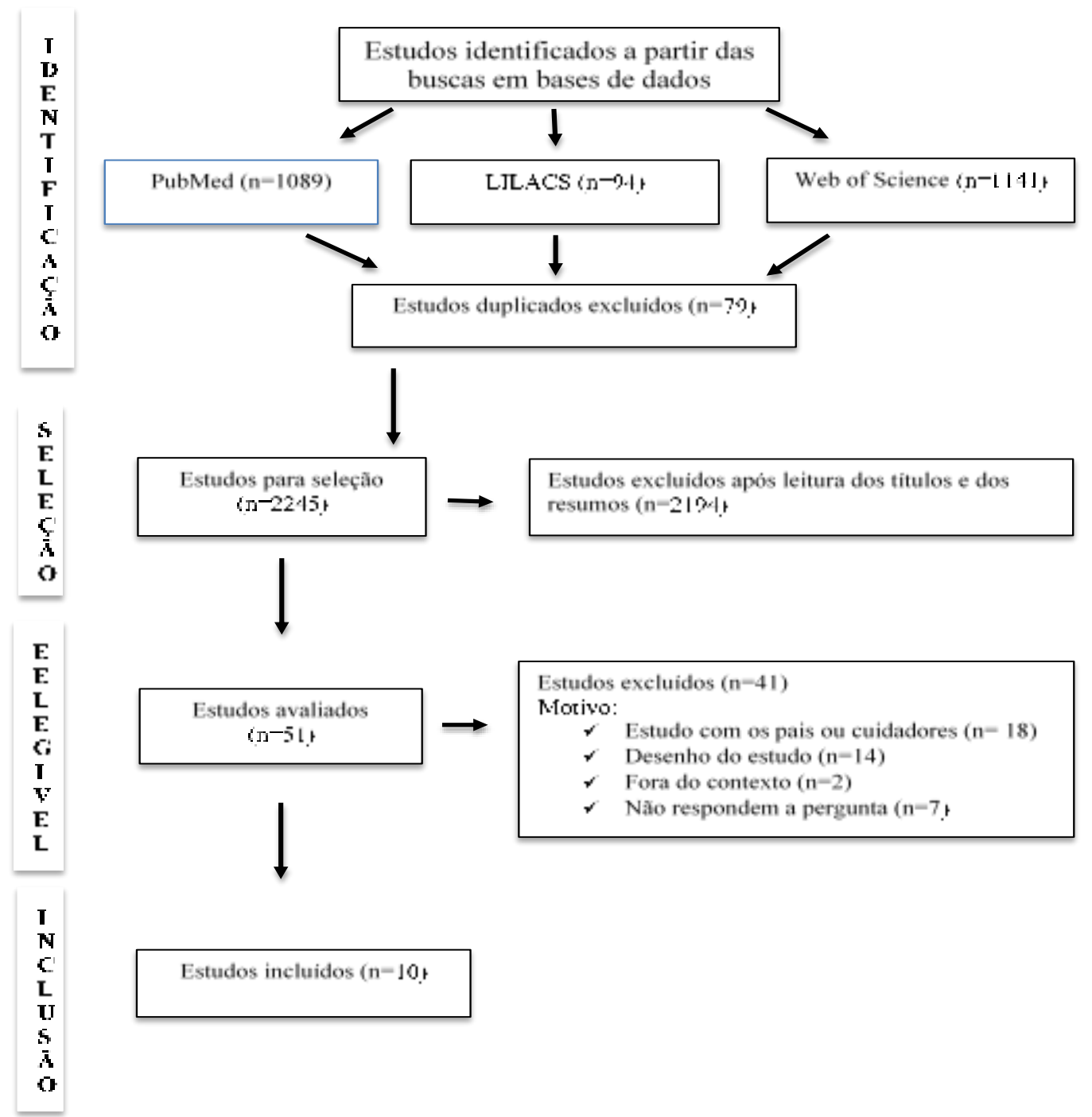

Fonte: Autores.

A amostra inicial foi composta por 51 artigos e para a amostra final foram selecionados 10 artigos cujos países são: Espanha $(n=5)$, Índia $(n=2)$, China $(n=1)$, Brasil $(n=1)$, Itália $(n=1)$; na língua inglesa $(n=8)$ e espanhola $(n=2)$ e foram classificados com nível de evidência IV $(n=4)$. No que se refere ao tipo de questão clínica, quatro foram de Significado (nível II, n=4), três estudos foram classificados como de Prognóstico/Predição ou Etiologia (nível IV, n=3) e três de Intervenção/Tratamento ou Diagnóstico/Teste Diagnóstico (nível VI, n=3). 
Quadro 1 - Características gerais dos estudos incluídos na Revisão Integrativa. Alfenas-MG, Brasil (2021).

\begin{tabular}{|c|c|c|c|c|c|}
\hline Número & Autor & Periódico & Idioma & País & $\begin{array}{l}\text { Nível de } \\
\text { evidência }\end{array}$ \\
\hline 1 & Avila et al. (2020) & $\begin{array}{l}\text { International Journal of Environmental } \\
\text { Research and Public Health }\end{array}$ & Inglês & Brasil & IV \\
\hline 2 & $\begin{array}{l}\text { Idoiaga, Berasategi, Eiguren, \& } \\
\text { Picaza (2020) }\end{array}$ & Frontiers in Psychology & Inglês & Espanha & II \\
\hline 3 & Lazzeroni et al. (2020) & Acta Biomedica & Inglês & Itália & IV \\
\hline 4 & Lopez e Prieto (2020) & Nutrición clínica y dietética hospitalaria & Espanhol & Espanha & IV \\
\hline 5 & Maan et al. (2020) & $\begin{array}{l}\text { Indian Journal of Otolaryngology and } \\
\text { Head \& Neck Surgery }\end{array}$ & Inglês & India & VI \\
\hline 6 & $\begin{array}{l}\text { Mondragon, Sancho, Santamaria, } \\
\text { \& Munitis (2020) }\end{array}$ & Psychology \& Health & Inglês & Espanha & II \\
\hline 7 & $\begin{array}{l}\text { Ruiz-Eugenio, Roca-Campos, } \\
\text { León-Jiménez, \& Ramis-Salas } \\
(2020)\end{array}$ & Frontiers in Psychology & Inglês & Espanha & VI \\
\hline 8 & $\begin{array}{l}\text { Singh, Haokip, Rathore, Vig, \& } \\
\text { Bhatnagar (2020) }\end{array}$ & Indian Journal of Palliative Care & Inglês & India & VI \\
\hline 9 & Tíscar-Gonzalez et al. (2020) & Gaceta Sanitaria & Espanhol & Espanha & II \\
\hline 10 & Xue et al. (2020) & Children and Youth Services Review & Inglês & China & IV \\
\hline
\end{tabular}

Fonte: Dados do estudo (2021).

Quadro 2 - Principais características dos estudos selecionados na Revisão Integrativa. Alfenas-MG, Brasil (2021).

\begin{tabular}{|c|c|c|c|}
\hline Número & Tipo de estudo & Objetivo & Principais resultados e conclusões \\
\hline 1 & $\begin{array}{c}\text { Estudo } \\
\text { transversal de } \\
\text { abordagem } \\
\text { quantitativa }\end{array}$ & $\begin{array}{l}\text { Avaliar a prevalência } \\
\text { de ansiedade em } \\
\text { escolares brasileiros } \\
\text { e estudar os fatores } \\
\text { de } \\
\text { associados ansiedade } \\
\text { distanciamento social } \\
\text { durante a pandemia } \\
\text { global de } \text { COVID- } \\
19 .\end{array}$ & $\begin{array}{l}289 \text { Crianças de } 6 \text { a } 12 \text { anos participaram do estudo através de uma plataforma online, } \\
\text { com avaliação sociodemográfica e as condições atuais quanto ao distanciamento e o } \\
\text { isolamento devido a pandemia. Maiores níveis de ansiedade estavam ligados ao } \\
\text { distanciamento social, ao número de pessoas em casa, a idade dos responsáveis e ao } \\
\text { nível de escolaridade dos responsáveis. Na pesquisa, as crianças que preservaram } \\
\text { distanciamento social com seus genitores apontaram escores mais baixos de ansiedade } \\
\text { em relação a outros indivíduos que não fossem seus pais }(\mathrm{p}=0,002) \text {. A prevalência de } \\
\text { ansiedade foi } 19,4 \%(\mathrm{n}=56) \text {, sendo para as meninas } 21 \%(\mathrm{n}=33) \text { e, para os meninos, } \\
\text { de } 17,4 \% \text { ( }=23) \text {. Houve um predomínio de ansiedade em crianças com pais com } \\
\text { trabalhos essenciais } 31,4 \% \text { ( }=16) \text { e os que mantinham isolamento sem os pais } \\
(35,7 \%, n=20) \text {. A prevalência de ansiedade foi maior em crianças isoladas com outras } \\
\text { pessoas que não fossem seus pais }(28,6 \% \text {, } n=16) \text {. As crianças que os responsáveis } \\
\text { apresentavam um nível educacional maior, tinham uma melhor compreensão da } \\
\text { pandemia do que as crianças com pais com nível educacional menor. A ansiedade nas } \\
\text { crianças que compreenderam a pandemia e as que não compreenderam não } \\
\text { apresentaram mudanças significativas. Essas descobertas sugerem a necessidade de } \\
\text { implementação de ações de saúde pública voltadas para esses pais e seus filhos no } \\
\text { nível populacional. }\end{array}$ \\
\hline 2 & $\begin{array}{c}\text { Estudo } \\
\text { qualitativo }\end{array}$ & $\begin{array}{lr}\text { Estudar como as } \\
\text { crianças entendem ou } \\
\text { representam ra } \\
\text { COVID-19, } \\
\text { observando r sua } \\
\text { resposta emocional à } \\
\text { pandemia } & \text { de } \\
\text { coronavírus } & \text { na } \\
\text { Espanha. } & \end{array}$ & $\begin{array}{l}\text { Uma amostra de } 250 \text { crianças de } 3 \text { a } 12 \text { anos participaram do estudo. Os participantes } \\
\text { responderam a duas perguntas de uma pesquisa online enviada no e-mail de seus pais } \\
\text { sobre o coronavírus. O estudo avaliou as principais ideias das crianças por meio de } \\
\text { associação livre. As ideias foram separadas em dois grupos, onde no primeiro, } \\
\text { relacionado a COVID-19 as crianças relatavam como um inimigo, entretanto também } \\
\text { citavam palavras como médico, vitória, bravo, sacada ou palmas, enaltecendo o } \\
\text { trabalho dos médicos que lutam contra o vírus e expondo o que devem fazer é } \\
\text { permanecer em casa. As crianças também descreveram o "medo de coronavírus" e } \\
\text { mostra as emoções de medo, preocupação, tristeza e nervosismo desenvolvidas por } \\
\text { este momento. Todavia, crianças apresentam um receio maior em infectar os avós do } \\
\text { que elas mesmas, mencionando inclusive que se sentiriam culpadas se isto ocorresse. } \\
\text { No segundo grupo, a ideia principal foi o isolamento devido a pandemia. Crianças }\end{array}$ \\
\hline
\end{tabular}




\begin{tabular}{|c|c|c|c|}
\hline & & & $\begin{array}{l}\text { expõem o desejo de saber quando voltarão à escola e à vida normal. Muitos também } \\
\text { demonstram preocupação se ficarão isolados em datas importantes, como seus } \\
\text { aniversários e também que se sentem seguros e protegidos em casa com seus } \\
\text { familiares. Analisando-se, percebe claramente que o coronavírus evoca susto - terror e } \\
\text { medo - nas crianças. Esse medo associa-se a possibilidade de infectar os avós, com o } \\
\text { sentimento de culpa. As crianças também se preocupam se os médicos matarão o } \\
\text { vírus (COVID-19). Compreender os padrões emocionais ligados para a atual } \\
\text { pandemia da voz daqueles que são mais vulneráveis, ou seja, crianças, e identificar } \\
\text { como eles cognitivamente representar e enfrentar emocionalmente esta nova situação } \\
\text { poderia propiciar estratégias a fim de ajudá-los a lidar com a crise de um ponto de } \\
\text { vista psicológico e emocional. }\end{array}$ \\
\hline 3 & Relato de caso & 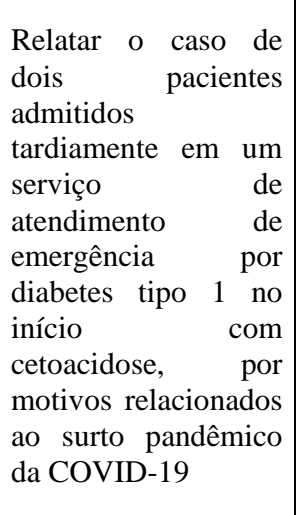 & $\begin{array}{l}\text { Uma criança de } 5 \text { anos de idade deu entrada na emergência devido a complicações } \\
\text { graves da diabetes tipo } 1 \text {. Ele teve perda de peso e dificuldade respiratória durante } \\
\text { uma semana antes de procurar a emergência. Uma menina de } 10 \text { anos também deu } \\
\text { entrada na emergência com dificuldade respiratória, poliúria, polidipsia há duas } \\
\text { semanas. A criança teve perda de peso e fadiga há pelo menos um mês. Os achados } \\
\text { laboratoriais confirmaram o diagnóstico de diabetes tipo } 1 \text {. Os pais relataram que o } \\
\text { medo de se infectar com o vírus da COVID- } 19 \text { foi responsável pelo atraso ao acesso e } \\
\text { a procura aos serviços de saúde. É necessário, mesmo durante uma pandemia, manter } \\
\text { programas educacionais dirigido a profissionais de saúde e aos pais e cuidadores em } \\
\text { relação aos sintomas de diabetes tipo } 1 \text {. Além disso, considerando a possibilidade } \\
\text { emergente de uma 'segunda onda' de pandemia COVID-19, é necessário que a } \\
\text { opinião pública e os profissionais de saúde forneça informações corretas sobre o } \\
\text { acesso aos serviços de saúde a fim de evitar o acesso tardio à emergência e para } \\
\text { prevenir morbidade e mortalidade evitáveis. }\end{array}$ \\
\hline 4 & $\begin{array}{c}\text { Estudo } \\
\text { transversal de } \\
\text { abordagem } \\
\text { quantitativa }\end{array}$ & $\begin{array}{l}\text { Analisar a relação } \\
\text { entre ansiedade, } \\
\text { estado de peso e } \\
\text { qualidade da dieta } \\
\text { em uma amostra de } \\
\text { estudantes do ensino } \\
\text { fundamental durante } \\
\text { o estado de } \\
\text { decretadorme } \\
\text { COVID-19 }\end{array}$ & $\begin{array}{l}116 \text { escolares de } 8 \text { a } 12 \text { anos participaram da pesquisa ( } 62 \text { homens e } 54 \text { mulheres). } \\
\text { Eles responderam a um questionário online com perguntas sociodemográficas e uma } \\
\text { Escala de Ansiedade Infantil Rio Spence (SCAS) para medir a ansiedade. O estudo } \\
\text { evidenciou mudanças consideráveis no peso }(<0,043) \text { e no nível de ansiedade global } \\
(<0,024) \text {. O aumento de peso nas crianças foi estatisticamente significante com } \\
\text { ataques de pânico e agorafobia (p }<0,036) \text { e transtorno de ansiedade generalizada (p } \\
<0,025) \text {. De outro modo, analisando mudanças dimensionais da ansiedade } \\
\text { considerando a qualidade da dieta classificada como improvável ou ideal nenhuma } \\
\text { alteração significante foi encontrada em quaisquer dimensões da ansiedade (p }>0,05) \text {. } \\
\text { A análise ANOVA não encontrou alterações significativas no meio dos escolares } \\
\text { (p }>0,05) \text {. Evidencia-se que os que aprestam peso adequado e dieta favorável tem } \\
\text { níveis de ansiedade inferiores. Conclui-se que os escolares que mantêm } \\
\text { comportamentos mais saudáveis, como o peso e uma dieta de qualidade ideal, obtêm, } \\
\text { para todas as dimensões, níveis de ansiedade mais baixos do que seus pares em } \\
\text { sobrecarga de peso e uma qualidade da dieta que pode ser melhorado. }\end{array}$ \\
\hline 5 & Relato de caso & 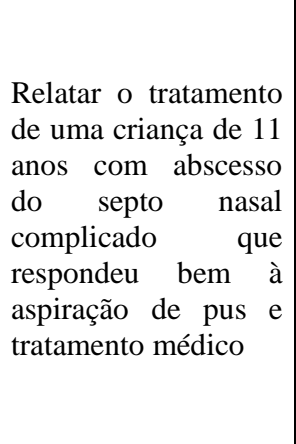 & $\begin{array}{l}\text { Um menino de } 11 \text { anos foi acolhido no departamento de otorrinolaringologia com } \\
\text { queixa de febre, inchaço no nariz e pálpebras há } 4 \text { dias. Não havia sintomas gripais. } \\
\text { De acordo com o pai, o paciente apresentou um edema nasal e foi medicado por um } \\
\text { médico local devido as restrições do COVID, porém sem sucesso na melhora dos } \\
\text { sintomas apresentando então um agravamento do caso. Temperatura de } 38^{\circ} \mathrm{C} \text {, } \\
\text { saturação de oxigênio de } 99 \% \text {, frequência cardíaca de } 100 \mathrm{bpm} \text {, frequência respiratória } \\
\text { de } 20 \mathrm{mpm} \text { e pressão arterial de } 104 / 90 \mathrm{mmHg} \text {. Devido a pandemia e as condições } \\
\text { clínicas do paciente, foi colhido um exame de swab nasal, com resultado negativo } \\
\text { para COVID-19. Após } 4 \text { horas internado, o paciente deu início a sintomas } \\
\text { característicos de meningite e os achados gerais foram de uma coleção de pus no } \\
\text { plano subpericondrial e subperiosteal do septo. O diagnóstico precoce e a intervenção } \\
\text { cirúrgica imediata são necessário junto com o tratamento antibiótico parenteral. }\end{array}$ \\
\hline 6 & $\begin{array}{l}\text { Estudo } \\
\text { qualitativo }\end{array}$ & $\begin{array}{l}\text { Estudar o impacto do } \\
\text { isolamento COVID- } \\
19 \text { nas crianças, visto } \\
\text { de sua perspectiva, } \\
\text { enquanto observando } \\
\text { suas respostas } \\
\text { emocionais em meio } \\
\text { à pandemia de } \\
\text { coronavírus r na } \\
\text { Espanha. }\end{array}$ & $\begin{array}{l}250 \text { crianças de } 3 \text { a } 12 \text { anos participaram do estudo. Os pais receberam por e-mail um } \\
\text { questionário onde teriam o papel de entrevistador com seus filhos, realizando três } \\
\text { perguntas relacionadas a quarentena. Os resultados foram coletados a partir das } \\
\text { principais ideias das crianças em relação ao bloqueio e separados em dois grupos: } \\
\text { antes do isolamento e depois do isolamento. O primeiro se refere a situação das } \\
\text { crianças durante o bloqueio e é constituído pelas classes } 4 \text { (Como me sinto?) e pala } \\
\text { classe } 1 \text { (O que estou fazendo?). O segundo grupo refere-se as coisas que as crianças } \\
\text { não possuem atualmente durante o bloqueio, compostos pelas classes } 2 \text { (O que eu } \\
\text { quero fazer?) e } 3 \text { (Quem/ O que sinto falta?). A primeira classe (4) teve um peso de } \\
\text { 20,8\%, nela as crianças informaram sentimentos de tristeza, nervosismo, preocupação } \\
\text { ou solidão, que são ligados ao bloqueio e ao coronavírus. Já na classe } 1 \text { teve um peso } \\
\text { de } 31,29 \% \text { e as crianças descreveram como realizam seus trabalhos escolares, e o que }\end{array}$ \\
\hline
\end{tabular}




\begin{tabular}{|c|c|c|c|}
\hline & & & $\begin{array}{l}\text { estão fazendo durante a quarentena como desenhar, brincar, ler ou cozinhar, uso de } \\
\text { tecnologias. Nessa classe, elas expressaram sentimentos tanto de felicidade como de } \\
\text { tédio e raiva. No segundo cluster, a classe } 2 \text { teve um peso de } 22,42 \% \text { e mostrou que as } \\
\text { crianças sentiam falta do ar livre, e relataram as atividades que gostariam de fazer } \\
\text { após o bloqueio como andar de bicicleta, ir a montanha, nadar, jogar futebol, entre } \\
\text { outras. A classe } 3 \text { teve um peso de } 25,49 \% \text { e expos o que ou quem as crianças mais } \\
\text { sentiam falta, exemplificadas por sentir falta dos primos, avós, colegas de escola e } \\
\text { também das atividades esportivas e das férias. Pode ser percebido através da análise } \\
\text { dos sentimentos das crianças que o bloqueio causa sentimentos confusos a elas. Em } \\
\text { síntese, os protocolos de distanciamentos social parecem ser eficazes para ajudar a } \\
\text { desacelerar a pandemia, mas repercutem no bem-estar das crianças. Assim, para } \\
\text { mitigar eventuais danos e prevenir outras dificuldades e efeitos negativos no futuro } \\
\text { (incluindo físicos, sociais e psicológicos problemas) como resultado de uma situação } \\
\text { já extrema, será essencial para os governos e autoridades locais desenvolverem } \\
\text { políticas sociais e inclusivas que atender às necessidades psicológicas, sociais, de } \\
\text { saúde e de bem-estar das crianças. }\end{array}$ \\
\hline 7 & $\begin{array}{l}\text { Estudo } \\
\text { qualitativo }\end{array}$ & 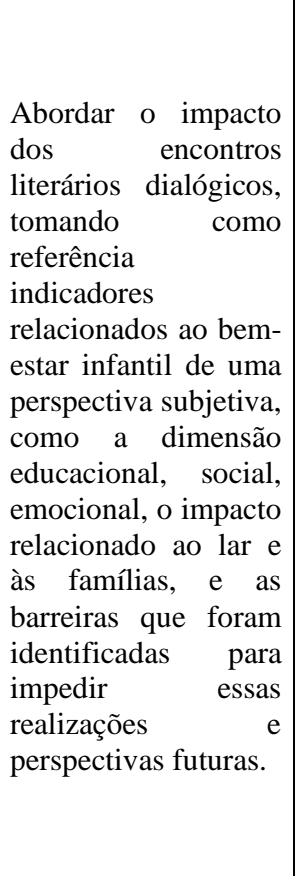 & $\begin{array}{l}\text { O estudo foi realizado através dos dados de dois grupos focais comunicativos com } \\
\text { professores de seis escolas, seis histórias de vida comunicativas com alunos. Os seis } \\
\text { Encontros Literários Dialógicos (ELD), que foi o objeto de análise do estudo, já } \\
\text { estava implementado nas escolas antes do confinamento e ocorreram de forma online. } \\
\text { Eles foram analisados para entender a sua contribuição para o bem-estar das crianças. } \\
\text { A análise observou os indicadores de bem-estar infantil e como eles impactaram seus } \\
\text { sentimentos e até mesmo em relação ao lar e as famílias em tempos de confinamento. } \\
\text { Os resultados dividem-se de acordo com as dimensões do bem-estar infantil, (a) } \\
\text { educacional; (b) social; (c) fatores emocionais, ou (d) o impacto nas famílias, bem } \\
\text { como (c) os desafios surgidos nesta nova situação e concepções futuras, de acordo } \\
\text { com a vivência dos participantes. Os alunos acreditam que a leitura e o debate são } \\
\text { muito úteis para a aprendizagem de ferramentas, especialmente na aquisição de } \\
\text { vocabulário, desenvolvimento de pensamento e expressão oral, sem serem } \\
\text { prejudicados pela mídia online. Os ELD também interferiram positivamente nos } \\
\text { hábitos das crianças, tanto nos gerenciamentos da rotina diária, quanto no próprio } \\
\text { amadurecimento do hábito de leitura. O fato de se encontrarem online com os ELD } \\
\text { tem ajudado os alunos a entenderem melhor a nova situação. Interações sociais de } \\
\text { qualidade, cruciais para o bem-estar, ocorrem em confinamento por meio de ELD } \\
\text { online. Os participantes expressaram seu desejo de continuar com este ação, } \\
\text { independentemente da situação de pandemia, e dada a sua complementaridade com o } \\
\text { formato presencial, parece plausível pensar que esta ação educativa viverá além do } \\
\text { surto, como uma ferramenta útil e bem-sucedida para impulsionar educação infantil e, } \\
\text { acima de tudo, o bem-estar infantil como bem como de suas famílias, incentivando a } \\
\text { criação de um amplo comunidade e uma participação mais ampla. }\end{array}$ \\
\hline 8 & Relato de caso & 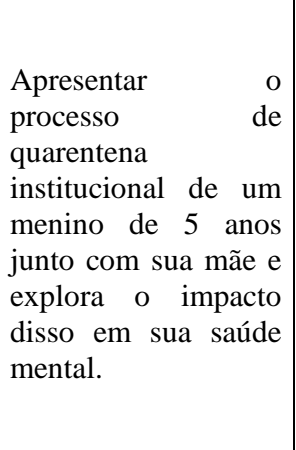 & $\begin{array}{l}\text { Uma criança de } 5 \text { anos foi transferida para isolamento social com sua mãe devido } \\
\text { diagnóstico positivo para COVID-19. Apresentava sintomas leves como coriza e tosse } \\
\text { seca. Devido ao isolamento a criança inicialmente ficou intrigada. Ele percebeu que } \\
\text { sua mãe não compartilhava a cama com ele e mantinha distância, o proibindo de sair } \\
\text { para brincar na rua. Não havia televisões ou brinquedos e seu pai e irmã não podiam } \\
\text { visita-lo. Ele apresentou desconforto com o confinamento e foi levado a entender que } \\
\text { era essencial ficar dentro de casa para que melhorasse seu estado de saúde, porém } \\
\text { estava se tornando difícil para ele lidar com a situação. Este caso fornece uma visão } \\
\text { sobre a importância de aumentar a comunicação, fazendo exercícios colaborativos } \\
\text { para abordar as preocupações das crianças e aliviar sua solidão. Além disso, destaca o } \\
\text { papel do cuidador no auxílio à recuperação e no conforto psicossocial essencial às } \\
\text { crianças acometidas, tornando-se um recurso indispensável para a equipe. }\end{array}$ \\
\hline 9 & $\begin{array}{c}\text { Estudo } \\
\text { exploratório } \\
\text { qualitativo }\end{array}$ & $\begin{array}{l}\text { Explorar as vivências } \\
\text { de escolares em } \\
\text { situação excepcional } \\
\text { de alerta sanitário, } \\
\text { em que medidas } \\
\text { rígidas }\end{array}$ & $\begin{array}{l}\text { Participaram desse estudo } 71 \text { escolares de } 7 \text { a } 8 \text { anos, dos quais } 58,3 \% \text { eram meninas } \\
13 \% \text { residiam na província de Álava, } 11,1 \% \text { em Guipúzcoa e } 66,7 \% \text { em Biscaia. A } \\
\text { análise de ilustrações foi a opção escolhida para este estudo, em uma folha em branco, } \\
\text { os alunos desenhavam como se sentiam em relação a situação de confinamento. Para } \\
\text { participar, eles precisavam responder à pergunta "Descreva em três palavras como } \\
\text { você se sente sobre a situação do coronavírus". Dentre os sentimentos o que mais } \\
\text { apareceu foi a tristeza, em } 47,88 \% \text {, seguido do medo em } 18,3 \% \text { e em terceiro o tédio } \\
\text { em } 14,08 \% \text {. Outros sentimentos referidos foram pesar e solidão, ambos em } 5,63 \% \text {. } \\
\text { Nem todos os escolares apresentaram reações negativas, } 7,04 \% \text { relataram sentir-se } \\
\text { "bem" e estar calmos, confortáveis e seguros, apesar de expressassem sentimento de } \\
\text { tristeza. Da análise dos conteúdos, } 5 \text { categorias foram ressaltadas como principais, } \\
\text { sendo elas sentimento de tristeza e medo; importância do núcleo familiar, segurança e } \\
\text { proteção; hábitos de vida sedentários durante o confinamento; infraestrutura }\end{array}$ \\
\hline
\end{tabular}




\begin{tabular}{|c|c|c|c|}
\hline & & \begin{tabular}{|l|} 
aplicadas \\
população.
\end{tabular} & $\begin{array}{l}\text { habitacional e desigualdades sociais (vida atrás de uma janela); resposta social, luta } \\
\text { coletiva ou do pessoal de saúde. Os sentimentos foram apresentados na forma de } \\
\text { desenhos, sendo vinte e cinco expondo sentimentos claros de tristeza e solidão devido } \\
\text { a impossibilidade de interagirem com amigos e familiares. Treze escolares } \\
\text { vivenciaram a situação de isolamento como a ocasião para afunilar os laços com a } \\
\text { família, trazendo sensações de bem-estar e segurança. Sete desenhos compreenderam } \\
\text { os perigos do isolamento para a saúde das crianças devido hábitos sedentários. Dez } \\
\text { desenhos mostraram a diferença social devido a infraestrutura da casa. Por fim, } 16 \\
\text { desenhos exibiram a luta social contra o inimigo que no caso seria o coronavírus. Os } \\
\text { alunos precisam se socializar e praticar esporte como parte de um desenvolvimento } \\
\text { psicomotor e psicossocial saudável. É necessário desenvolver um plano de } \\
\text { contingência para o futuro situações de alarme que garantem o bem-estar físico e } \\
\text { psicológico de menores, bem como a regulamentação da atividade não presencial e a } \\
\text { interação dos diferentes centros com os alunos durante o confinamento em casa. }\end{array}$ \\
\hline 10 & $\begin{array}{c}\text { Estudo } \\
\text { epidemiológico } \\
\text { transversal de } \\
\text { abordagem } \\
\text { quantitativa }\end{array}$ & $\begin{array}{l}\text { Investigar os } \\
\text { conhecimentos, } \\
\text { atitudes e práticas } \\
\text { para COVID-19 } \\
\text { entre alunos de duas } \\
\text { escolas primárias na } \\
\text { cidade de Wuhan e } \\
\text { Huangshi, província } \\
\text { de Hubei, durante o } \\
\text { surto de COVID-19 }\end{array}$ & $\begin{array}{l}1650 \text { crianças da } 2^{\mathrm{a}} \text { a } 6^{\mathrm{a}} \text { série responderam a um questionário por meio de uma } \\
\text { plataforma online que incluíam características demográficas, conhecimentos sobre a } \\
\text { COVID-19 composto por } 12 \text { questões e práticas durante a pandemia e também os } \\
\text { sintomas de depressão e ansiedade. Constatou-se que } 22,4 \% \text { das crianças } \\
\text { apresentaram sintomas depressivos e } 18,8 \% \text { apresentaram sintomas de ansiedade. Os } \\
\text { alunos apresentaram } 70,1 \%-99,5 \% \text { de níveis de conscientização, como separar as } \\
\text { tábuas e facas para alimentos crus e cozidos e comprar carne de frango resfriada, } 2,1 \% \\
\text { dos participantes consideraram a visita a parentes e amigos uma conduta aceitável } \\
\text { perante a pandemia. Aproximadamente, metade dos alunos estavam otimistas com a } \\
\text { pandemia e } 37,2 \% \text { apresentavam-se preocupados em contrair o vírus. A grande } \\
\text { maioria (93,7\%) afirmou que lavavam as mãos com frequência, porém } 85,6 \% \text { disse } \\
\text { lavar as mãos ao tossir ou espirrar. Os escores gerais de conhecimentos, atitudes e } \\
\text { práticas dos alunos em relação ao COVID-19 foram notadamente associados a gênero, } \\
\text { série e se eles tinham sintomas depressivos e de ansiedade. Estudantes com sintomas } \\
\text { depressivos tiveram pontuação inferiores em termos de conhecimentos, atitudes e } \\
\text { prática em relação aos assintomáticos depressivos. Da mesma forma, alunos com } \\
\text { sintomas de ansiedade tiveram pontuações inferiores comparados aos assintomáticos } \\
\text { ansiosos. Melhorar o nível de conhecimento, atitudes e práticas do COVID-19 é } \\
\text { essencial para a prevenção do ressurgimento do contágio. }\end{array}$ \\
\hline
\end{tabular}

Fonte: Dados do estudo (2021).

Remetendo-se à pergunta norteadora do estudo, evidenciou-se que as crianças experienciaram a pandemia da COVID19 em três campos sistematizados apresentados a seguir: Saúde mental, física e social. Vale ressaltar que alguns artigos são apresentados sob mais de uma perspectiva.

\section{Saúde Mental}

Nove artigos que compuseram a amostra do estudo detectaram resultados na saúde mental, sendo seis apresentando vivências de sofrimentos decorrentes da pandemia da COVID-19, um que apresenta aspectos positivos de bem-estar e um que apresenta resultados em ambas as dimensões.

Dois estudos espanhóis abordaram o entendimento e vivências das crianças em relação a COVID-19. Um dos estudos foi realizado através da análise das principais ideias das crianças (Idoiaga et al., 2020) e outro através da análise de desenhos realizados por elas (Tíscar-González et al., 2020). Em ambos os estudos foram descritas emoções como medo, preocupação, tristeza, nervosismo, raiva e solidão vivenciados nesse momento (Idoiaga et al., 2020; Tíscar-González et al., 2020).

Além desses sentimentos, as crianças mais velhas (de 6 a 12 anos) sentiram-se bastante preocupadas, uma vez que compreendem que a COVID-19 é altamente contagiosa. A maioria referência estar mais preocupada em infectar seus avós do que em serem infectadas (Idoiaga et al., 2020).

Um dos artigos avaliou a prevalência de ansiedade em escolares brasileiros e os fatores de ansiedade associados ao distanciamento social. Identificou uma taxa de ansiedade de $19,4 \%$ ( $n=56)$ e que as meninas apresentaram maiores níveis de 
ansiedade que os meninos. Também se identificou que os níveis mais elevados de ansiedade estavam relacionados a pais mais novos, baixa escolaridade dos pais, e estar com outras pessoas que não fossem seus pais (Avila et al., 2020).

Em outra investigação observou-se o aumento do peso corporal e o nível de ansiedade global nas crianças durante a pandemia. Constatou diferenças estatisticamente significantes entre essas variáveis: escolares com menor peso e uma dieta mais saudável apresentavam níveis de ansiedade menores que os escolares em sobrepeso (López \& Prieto, 2020).

O sentimento de solidão também foi referenciado em uma pesquisa na qual identificaram que as crianças sentiam falta de outras crianças, como amigos ou colegas de classe. Também mencionaram que sentem falta de alguns de seus cuidadores, como avós, professores ou treinadores (Mondragon et al., 2020).

Outro estudo identificou que crianças tinham uma consciência relativamente boa da COVID-19 durante a pandemia, bem como atitudes otimistas e práticas adequadas do autocuidado. Entretanto, $18,8 \%$ e 22,4\% das crianças apresentavam, respectivamente, sintomas de ansiedade e depressão; 37,2\% (613) dos participantes mostraram-se bastantes preocupados em estarem infectados com a COVID-19, sendo que aqueles com sintomas depressivos e de ansiedade tiveram pontuações mais baixas em termos de conhecimentos, atitudes e práticas em relação a COVID-19 do que aqueles sem sintomas (Xue et al., 2021).

Um relato de caso de uma criança que após história de contato com pacientes COVID positivados e sintomas leves foi colocado de quarentena institucional junto com a sua mãe. Inicialmente, observou que a criança apresentava um estranhamento quando se deparou com o isolamento familiar por suspeita da COVID-19. Ficou intrigada ao perceber que sua mãe não o estava deixando dividir a cama dela, mantinha-se distante dele e não permitia passeios. Depois da fase inicial de estranhamento, a criança tornou-se mais irritável e até agressiva (Singh et al., 2020).

Resultado positivo da pandemia foi descrito em um estudo que analisou treze desenhos das crianças que retrataram o núcleo da família unida, gerando uma sensação de calma, segurança e bem-estar (Tíscar-González et al., 2020).

Outro estudo espanhol identificou sentimentos de bem-estar das crianças que participavam de encontros literários online durante a pandemia. Os resultados foram relacionados as dimensões do bem-estar infantil no quesito educacional, social, fatores emocionais e impacto nas famílias. As crianças relataram que os debates eram muito úteis para a aprendizagem instrumental, aquisição de vocabulário, desenvolvimento do pensamento e da expressão oral, e que o meio online não os prejudicou em relação ao conhecimento. Os encontros literários também tiveram importante impacto positivo na manutenção da rotina diária, no fortalecimento do hábito de leitura, nas interações sociais de qualidade e na melhor compreensão da nova situação imposta pela pandemia da COVID-19. A nova situação permitiu que as famílias passassem mais tempo juntas, e os encontros literários permitiram o fortalecimento de laços pais e filhos, conforme a presença dos pais nos encontros, levando a conversas profundas e também a possibilidade de expressar sentimentos em casa (Ruiz-Eugenio et al., 2020).

\section{Saúde Social}

Nessa dimensão detectou-se dois artigos com resultados negativos da pandemia na vida das crianças. No estudo de Tiscar et al (2020), as crianças expressaram em alguns desenhos o sentimento de tristeza por não possuírem espaços abertos para brincar. O nível de desigualdade social pode ser percebido na discrepância entre os desenhos, no qual as crianças brincando no jardim de casa destoava dos desenhos de crianças com expressões de tristeza olhando pela janela.

Outra investigação apontou que o isolamento social pode ser uma ameaça real para a atividade física das crianças, estando fortemente ligado ao ganho de peso, perda da aptidão cardiorrespiratória e até piora da saúde mental. Neste estudo as crianças expressam uma série de atividades que gostariam de realizar, como andar de bicicleta, nadar, ir à montanha, brincar, dançar, correr, patinar ou jogar futebol. Algumas das crianças também expressam a necessidade de 'respirar' porque se sentem trancados, ou mesmo 'aprisionados'. O uso da linguagem figurada reflete as consequências de ser privado de ar fresco, o que 
tem um impacto muito profundo e holístico sobre eles, afetando as crianças fisicamente, emocionalmente e socialmente (Mondragon et al., 2020).

\section{Saúde Física}

Na terceira dimensão evidenciou-se dois artigos que demonstraram o impacto da pandemia na saúde física. Um estudo relatou o caso de uma criança de 11 anos com abscesso do septo nasal complicado que evoluiu de vestibulite a abscesso septal, levando a sinusite, complicações orbitais e intracranianas (Maan et al., 2020). O relato de caso foi incluído pois houve retardo no diagnóstico da condição de uma patologia simples devido ao distanciamento social no cenário da COVID-19.

Outro relato de caso mostrou que de duas crianças tiveram ou agravamento de uma situação clínica ou atraso de diagnóstico: o primeiro, uma criança de 5 anos de idade diabética (tipo 1) deu entrada na emergência devido a uma cetoacidose diabética grave. A outra confirmou o diagnóstico de diabetes tipo 1 depois de um retardo na busca da assistência médica. $\mathrm{O}$ medo de se infectar com o vírus da COVID-19 foi responsável pelo atraso ao acesso e a procura aos serviços de saúde (Lazzeroni et al., 2020).

\section{Discussão}

A pandemia da COVID-19 tem ocasionado diversas repercussões na saúde mental. Neste contexto, o número de pessoas afetadas psicologicamente tem sido maior que o número de pessoas infectadas pela doença. Estima-se que um terço da população, incluindo as crianças, possa apresentar consequências psicológicas se não receberem os cuidados adequados (Ornell, Schuch, Sordi, \& Kessler, 2020). Mesmo crianças saudáveis estão suscetíveis a problemas psicossociais com alterações emocionais e sociais (Tso et al., 2020).

Problemas de saúde mental podem dificultar a aquisição e retenção de informações sobre a prevenção da COVID-19, aprofundando assim o sentimento de incerteza (Xue et al., 2021). A intensidade do distanciamento social, a qualidade das relações familiares e o tempo de duração desse isolamento são variáveis importantes na avaliação dos prejuízos emocionais dessa medida (Brooks et al., 2020).

Pesquisas mostraram que grandes desastres podem ter impacto psicológico nas crianças como ansiedade (Chen et al., 2020), depressão (Yeasmin et al., 2020), ataques de pânico (Saurabh \& Ranjan, 2020), desatenção (Jiao et al., 2020; Spinelli, Lionetti, Pastore, \& Fasolo, 2020; Zhang et al., 2020) e irritabilidade (Orgilés, Morales, Delvecchio, Mazzeschi, \& Espada, 2020).

As consequências da ansiedade que impactam o bem-estar infantil envolvem danos escolares como a dificuldade de aprendizagem e os agravos sociais relacionados a amizades e relações familiares (Stallard, 2002). A vivência com sintomas de ansiedade e estresse pode levar a cicatrizes profundas na vida da criança (Yehuda, Halligan, \& Grossman, 2001).

A ansiedade na infância pode estar relacionada ao apetite e a ingestão alimentar excessiva, o que afeta o ganho de peso, o metabolismo e a insatisfação corporal. A obesidade infantil é considerada uma importante doença nutricional e seu crescimento é preocupante. Além disso, tem produzido impactos significativos na vida das crianças com consequências físicas, sociais e psicológicas (Mello et al., 2010). Hábitos adequados de vida, tanto na alimentação quanto na atividade física podem ter impactos positivos na saúde mental da criança (Escalante-Izeta, Haua-Navarro, Moreno-Landa, \& Pérez-Lizaur, 2016), mesmo em tempos de pandemia e restrições de deslocamento.

Um estudo evidenciou que os níveis mais elevados de ansiedade estavam relacionados a baixa escolaridade dos pais. Por sua vez, a baixa escolaridade dos pais está associada a uma baixa qualidade de vida nas crianças, constituindo-se um fator de risco para problemas de saúde mental infantil. Pais com maior status educacional podem passar mais tempo com os filhos 
melhorando a qualidade de vida para essas crianças (Sonego, Llácer, Galán, \& Simón, 2013). Ainda que outros fatores possam interferir, é importante considerar estes fatores.

A idade é fator crucial de como as crianças lidam com as consequências da pandemia: sendo positivamente relacionada a maiores vínculos sociais e estratégias de coping (Domínguez-Álvarez, López-Romero, Isdahl-Troye, GómezFraguela, \& Romero, 2020). As crianças mais velhas podem demonstrar sentimentos de resolução de problemas, entender como as coisas acontecem ou buscar apoio social, apesar do desânimo e raiva devido à paralisação das escolas, o cancelamento de viagens, o isolamento e distanciamento de seus amigos e parentes (Ghosh, Dubey, Chatterjee, \& Dubey, 2020). Por sua vez, demonstram maior dificuldade na realização de tarefas escolares (Giménez-Dasí, Quintanilla, Lucas-Molina, \& SarmentoHenrique, 2020). As crianças mais novas pareceram ser mais afetadas durante a pandemia, pois exibiram mais problemas de conduta e sintomas de hiperatividade ou desatenção (Tso et al., 2020).

Não só a qualidade de vida mas também a qualidade das interações tende a ser prejudicada pelo nível mais elevado de angústias e preocupações. Por isso é importante manter a relação na ligação entre emoções e reações comportamentais, buscando fazer da sua comunicação uma situação de alívio, acolhimento e esperança (Manitto et al., 2020).

Uma importante ferramenta de intervenção é a comunicação colaborativa em que se aborda as preocupações das crianças e aliviar sua solidão. Além disso, o cuidador tem um papel fundamental no conforto psicossocial, tornando-se um recurso indispensável para a equipe (Singh et al., 2020).

O isolamento social também afetou a vida das crianças de forma "positiva". Algumas crianças sentiram o isolamento social como uma medida favorável em suas vidas por poderem passar mais tempo com suas famílias e estreitar laços com sua família (Tíscar-González et al., 2020).

A quarentena pode ser útil para aperfeiçoar a interação entre pai e filho e promover assim uma paternidade positiva (Cluver et al., 2020), podendo ser uma das razões pelas quais algumas crianças não apresentariam um agravamento em seus sintomas (Wang, Zhang, Zhao, Zhang, \& Jiang, 2020).

As crianças quando são afastadas das pessoas com quem tem vínculos, receiam nunca mais reencontrá-las e costumam expressar um sentimento de medo de que possa acontecer algum acidente ou doença com seus entes queridos (Assis, Ximenes, Avanci, \& Pesce, 2007). Por isso, é significativo manter os vínculos afetivos com familiares, ainda que usando os dispositivos de tecnologia (Thomazini \& Goulart, 2018).

Além disso, em um momento de isolamento, a oportunidade de dividir sentimentos tem sido valorizada como condição fundamental para o bem-estar infantil. O fato de estarem online pode ter ajudado os alunos a expressarem suas opiniões deixando a timidez de lado (Ruiz-Eugenio et al., 2020).

É importante que a escola ofereça aos alunos a oportunidade de interagir com os professores e obter aconselhamento psicológico (Mondragon et al., 2020). Por esse motivo, seria altamente desejável garantir que essa conexão direta entre professores e crianças também seja mantida durante esse período de confinamento (Wang et al., 2020). Instituições e centros de ensino devem propiciar estratégias que permitam às crianças manter contato com colegas e professores por meio de plataformas online. Deve-se notar, no entanto, que existem crianças (principalmente aquelas que são vulneráveis) que não têm acesso à Internet ou a computadores em casa e, portanto, devem ser tomadas medidas de acessibilidade educacionais.

As restrições que a pandemia impôs também se relacionam ao lazer e a comportamentos lúdicos: crianças e jovens ficaram menos ativos, brincaram menos fora de casa, participaram de mais atividades recreativas a partir de uma tela e dormiram mais durante a pandemia (Moore et al., 2020).

Também a questão medo de se contaminar e a alteração do funcionamento dos sistemas de saúde geraram uma redução no acesso aos serviços tanto em questão de prevenção, quanto em atendimentos, incluindo a redução de cirurgias eletivas e até mesmo tratamentos oncológicos e de cuidados de emergências em saúde (Fiocruz, 2020). 
Diversas questões estão interrelacionadas: o aumento do tempo total de tela talvez relacionado à diminuição das possibilidades de brincar, embora relacionada ao fechamento de escolas, também ocorre em decorrência da falta de espaço adequado para as crianças que não podem sair de casa (Silva et al., 2020).

O uso prolongado de dispositivos eletrônicos deve ser evitado. Os pais e educadores de crianças em idade pré-escolar devem aderir às recomendações da Academia Americana de Pediatria (AAP) para limitar o tempo de tela a menos de 1 hora por dia (Tso et al., 2020). Já a Sociedade Brasileira de Pediatria aconselha que crianças com menos de 2 anos não sejam expostas a telas e, para aquelas de dois a cinco anos, o tempo deve ser limitado a uma hora diária (Sociedade Brasileira de Pediatria, 2019).

Tanto por questões de saúde quanto por razões pedagógicas, o ensino a distância não é um recurso recomendável para crianças na primeira infância. Esse tipo de atividade está na contramão do que propõe a Base Nacional Curricular Comum [BNCC], que organiza o currículo na educação infantil por campos de experiência, reforçando a ideia que a criança aprende por meio de experiências concretas, interativas, lúdicas e integradoras de várias áreas de conhecimento. Esse tipo de atividade não consegue ser alcançada de forma virtual, pois a aprendizagem da criança tende a ser fragmentada e descontextualizada quando ela está exposta a telas, sem interações reais (Manitto et al., 2020).

A brincadeira pode ajudar as crianças a resistir ao isolamento (Graber et al., 2021). Então, é importante que as famílias busquem alternativas para que as crianças possam brincar. Diversas possibilidades se abrem para que as famílias consigam lidar com essa questão: reservar tempo para o lazer da família e começar novos hobbies e atividades (Brooks et al., 2020).

Entretanto é relevante considerar a realidade socioeconômica de muitas famílias, especialmente em países em desenvolvimento como no Brasil. Muitas famílias vivem em situação de exclusão socioeconômica e não tem estrutura e tempo para propiciar espaços adequados para brincadeiras e jogos, lazer ou hobbies (Aliança para a Proteção da Criança em Ações Humanitárias, 2020).

A restrição devido ao isolamento social pode ser uma ameaça real para a atividade física das crianças, estando fortemente ligados ao ganho de peso, perda da aptidão cardiorrespiratória e até piora da saúde mental (Mondragon et al., 2020).

O ambiente doméstico tem uma influência importante na atividade física e no comportamento sedentário das crianças pois seus ambientes fechados, falta de amigos e/ou falta de espaço impedem que os pequenos realizem atividades que acarretam um alto teor de perda calórica como aconteciam nas aulas de educação física nas escolas (Pombo, Luz, Rodrigues, Ferreira, \& Cordovil, 2020). Um medo preocupante é de que as mudanças de comportamento acometidas devido ao isolamento social se tornem permanentes aumentando o risco de obesidade, doenças cardiovasculares e diabetes a medida que as crianças vão se desenvolvendo (Dunton, Do, \& Wang, 2020).

Além de prevenir essas comorbidades, a prática de exercícios físicos é um fator protetor para reduzir os problemas comportamentais de crianças em idade escolar em distanciamento social. Fazer atividade física tem o potencial de reduzir os sintomas de hiperatividade-desatenção e problemas de comportamento em criança (Silva et al., 2020).

A exposição de curto prazo a desastres pode ser superada mas deixa as crianças mais vulneráveis a quaisquer interferências em um estágio posterior de desenvolvimento (Gutman, Joshi, \& Schoon., 2019). Portanto, um acompanhamento individualizado do comportamento das crianças é necessário para uma maior compreensão dos efeitos a longo prazo da quarentena domiciliar durante a pandemia da COVID-19. Também é importante o acompanhamento diferenciado já que os problemas comportamentais também podem variar com a idade (Liu et al., 2021).

A estrutura familiar tem se mostrado um claro diferenciador que investiga as desigualdades sociais durante a pandemia. O núcleo familiar assume especial relevância, fazendo com que os escolares se sintam protegidos e seguros. É 
necessário desenvolver um plano de contingência e recursos de treinamento que forneçam informações precisas e adaptadas à população infantil e que promovam hábitos de vida saudáveis no domicílio (Tíscar-González et al., 2020).

As crianças devem ser colocadas no centro dos Objetivos de Desenvolvimento Sustentável (Clark et al., 2020), sendo que o foco deve ser no apoio e envolvimento da família e em práticas baseadas na comunidade para garantir a segurança e o bem-estar das crianças (Child Welfare Information Gateway, 2020).

A responsabilidade não é apenas das famílias ou escolas, mas também dos governos para propor estratégias e evitar, na medida do possível, o impacto da pandemia da COVID-19 na saúde física e mental das crianças (Wang et al., 2020).

É importante considerar que os momentos de crise, como o da pandemia da COVID-19, constituem-se uma oportunidade para a implementação de políticas adequadas em relação a saúde das crianças (Jacob et al., 2020), seja em reestruturação e priorização de investimentos, seja para a tomada de decisão baseadas em dados, vontade e compromisso político e unidade internacional (Akseer, Kandru, Keats, \& Bhutta, 2020).

Isso é particularmente valoroso considerando que a pandemia da COVID-19 tem resultado em um número potencialmente grande de atrasos ou ausência do diagnóstico de doenças comuns na população, o que pode trazer riscos a toda a população (Ciacchini et al., 2020; Lynn, Avis, Lenton, Amin-Chowdhury, Ladhani, 2021; Sharpless, 2020; Williams et al., 2020). As consequências para o câncer, por exemplo, podem ser substanciais. Os cânceres perdidos agora ainda virão à luz eventualmente, mas em um estágio posterior ("upstaging”) e com prognósticos piores (Sharpless, 2020).

Por essa razão, são necessárias políticas que incluam planejamento para lidar com o grande acúmulo de pacientes que provavelmente devem procurar atendimento após o afrouxamento da quarentena. Além disso, estratégias nacionais de comunicação devem ser consideradas para garantir que pacientes com necessidades de consulta de urgência não deixem de procurar os serviços de saúde (Williams et al., 2020).

O desenvolvimento de políticas voltadas para garantir um desenvolvimento infantil saudável deve ser a base de uma sociedade produtiva que pretende criar um futuro de sucesso (Ruiz-Eugenio et al., 2020). Os programas e políticas públicas afetam diretamente as capacidades da comunidade para fortalecer esse desenvolvimento saudável, sustentado por contextos seguros e relações estáveis de qualidade (Center on the Developing Child of Harvard University, 2014).

A saúde mental pode ser melhorada através de programas de educação em saúde (Xue et al., 2021). Tanto a OMS quanto o Center for Disease Control and Prevention (CDC) recomendam o trabalho das equipes de Saúde Mental no enfrentamento de pandemias e desastres em larga escala (CDC, 2020). As crianças precisam receber uma atenção para explicar os fenômenos, permitir as expressões de sentimentos, estabelecer rotinas e responder questões, assim como compreender a irritabilidade e algumas regressões no comportamento que demandam atenção por parte dos cuidadores (Linhares \& Enumo, 2020).

A infância não tem a sua própria voz, exige atenção e cuidado especial da parte do cuidador para entender suas necessidades tanto físicas quanto emocionais para lidarem com as interferências da pandemia no seu desenvolvimento. As intervenções para esses problemas devem ser baseadas na cobertura individual, apoio familiar e da comunidade como escolas, serviços pediátricos, terapias (Manitto et al., 2020).

Neste sentido, devem ser priorizados esforços para aumentar a capacidade dos sistemas de cuidados familiares e de proteção social de forma preventiva para reforçar a resiliência dessas famílias, bem como salientar a importância dos pais na promoção da saúde mental dos filhos (Rodrigues \& Lins, 2020). Os governos e a sociedade civil devem planejar um forte para priorizar a permanência das crianças e adolescentes em seus ambientes familiares de forma segura. 


\section{Conclusão}

Este estudo forneceu uma revisão dos artigos que tratam dos impactos da pandemia na saúde mental, física e social das crianças e expõe seus principais efeitos. Remetendo-se a pergunta norteadora, as evidências disponíveis na literatura mostram problemas na saúde, envolvendo mudanças de comportamento, da ansiedade, da obesidade e do sedentarismo em crianças.

Principalmente durante a pandemia da COVID-19, as crianças necessitam de apoio dos pais e das instituições de ensino e de saúde para que esses problemas não afetem a sua vida futura. É indispensável que as autoridades entendam as necessidades das crianças e elaborem estratégias que diminuam esses impactos em seu bem-estar, com projetos que auxiliem a diminuir os danos causados durante a pandemia após o retorno das crianças para o mundo pós pandemia da COVID-19, garantindo novamente a inserção nas escolas, nas atividades cotidianas e nos serviços de prevenção de saúde.

A pandemia passará, porém, o desenvolvimento da criança continua e precisa ser protegido. Portanto, as evidências científicas demonstram que será preciso avaliar e intervir continuamente nos impactos da pandemia na saúde das crianças, além de propostas de medidas preventivas para mitigar os potenciais efeitos negativos e sequelas no desenvolvimento.

Como limitações de estudo, destaca-se a própria abordagem/desenho dos estudos encontrados, em sua maioria com uma amostra pequena, estudos transversais). Pela própria complexidade dos efeitos da pandemia, é fundamental posteriormente sejam realizados estudos longitudinais para identificar as repercussões na saúde das crianças no período póspandêmico.

\section{Referências}

Akseer, N., Kandru, G., Keats, E. C., \& Bhutta, Z. A. (2020). COVID-19 pandemic and mitigation strategies: Implications for maternal and child health and nutrition. The American Journal of Clinical Nutrition, 112(2), 251-256. https://doi.org/10.1093/ajcn/nqaa171

Aliança para a Proteção da Criança em Ações Humanitárias. (2020). Nota Técnica: Proteção da Criança durante a Pandemia do Coronavírus. UNICEF.

Assis, S. G., Ximenes, L. F., Avanci, J. Q., \& Pesce, R. P. (2007). Ansiedade em crianças: Um olhar sobre transtornos de ansiedade e violências na infância. FIOCRUZ/ENSP/CLAVES/CNPq. http://www5.ensp.fiocruz.br/biblioteca/dados/txt_530050460.pdf

Avila, M. A. G., Hamamoto Filho, P. T., Jacob, F. L. S., Alcantara, L. R. S., Berghammer, M., Nolbris, M. J., Olaya-Contreras, P., \& Nilsson, S. (2020). Children's Anxiety and Factors Related to the COVID-19 Pandemic: An Exploratory Study Using the Children's Anxiety Questionnaire and the Numerical Rating Scale. International Journal of Environmental Research and Public Health, 17(16). https://doi.org/10.3390/ijerph17165757

Bergmann, G. G., Cunha, G. B., Cunha, G. O. K., Cruz, J. H. B., Silva, L. R., Ferreira, G. D., \& Pinheiro, E. S. (2020). Changes in body weight and health behaviors of overweight children during the COVID-19 pandemic. Revista Brasileira de Atividade Física \& Saúde, 25, 1-7. https://doi.org/10.12820/rbafs.25e0153

Bezerra, A. C. V., Silva, C. E. M., Soares, F. R. G., \& Silva, J. A. M. (2020). Fatores associados ao comportamento da população durante o isolamento social na pandemia de COVID-19. Ciência \& Saúde Coletiva, 25, 2411-2421. https://doi.org/10.1590/1413-81232020256.1.10792020

Brooks, S. K., Webster, R. K., Smith, L. E., Woodland, L., Wessely, S., Greenberg, N., \& Rubin, G. J. (2020). The psychological impact of quarantine and how to reduce it: Rapid review of the evidence. The Lancet, 395(10227), 912-920. https://doi.org/10.1016/S0140-6736(20)30460-8

Center Disease for control (CDC). (2020). COVID-19 and Your Health. Centers for Disease Control and Prevention. https://www.cdc.gov/coronavirus/2019ncov/daily-life-coping/managing-stress-anxiety.html

Center on the Developing Child of Harvard University. (2014). InBrief: The Foundations of Lifelong Health. Center on the Developing Child. https://developingchild.harvard.edu/resources/the-foundations-of-lifelong-health-are-built-in-early-childhood/

Chen, F., Zheng, D., Liu, J., Gong, Y., Guan, Z., \& Lou, D. (2020). Depression and anxiety among adolescents during COVID-19: A cross-sectional study. Brain, Behavior, and Immunity, 88, 36-38. https://doi.org/10.1016/j.bbi.2020.05.061

Child Welfare Information Gateway. (2020). Supporting \& Preserving Families. U.S. Department of Health and Human Services. https://www.childwelfare.gov/

Ciacchini, B., Tonioli, F., Marciano, C., Faticato, M. G., Borali, E., Pini Prato, A., \& Felici, E. (2020). Reluctance to seek pediatric care during the COVID-19 pandemic and the risks of delayed diagnosis. Italian Journal of Pediatrics, 46(1), 87. https://doi.org/10.1186/s13052-020-00849-w

Clark, H., Coll-Seck, A. M., Banerjee, A., Peterson, S., Dalglish, S. L., Ameratunga, S., Balabanova, D., Bhan, M. K., Bhutta, Z. A., Borrazzo, J., Claeson, M., Doherty, T., El-Jardali, F., George, A. S., Gichaga, A., Gram, L., Hipgrave, D. B., Kwamie, A., Meng, Q., \& Costello, A. (2020). A future for the world's children? A WHO-UNICEF-Lancet Commission. The Lancet, 395(10224), 605-658. https://doi.org/10.1016/S0140-6736(19)32540-1 
Cluver, L., Lachman, J. M., Sherr, L., Wessels, I., Krug, E., Rakotomalala, S., Blight, S., Hillis, S., Bachman, G., Green, O., Butchart, A., Tomlinson, M., Ward, C. L., Doubt, J., \& McDonald, K. (2020). Parenting in a time of COVID-19. The Lancet, 395(10231), e64. https://doi.org/10.1016/S01406736(20)30736-4

Domínguez-Álvarez, B., López-Romero, L., Isdahl-Troye, A., Gómez-Fraguela, J. A., \& Romero, E. (2020). Children Coping, Contextual Risk and Their Interplay During the COVID-19 Pandemic: A Spanish Case. Frontiers in Psychology, 11. https://doi.org/10.3389/fpsyg.2020.577763

Dunton, G. F., Do, B., \& Wang, S. D. (2020). Early effects of the COVID-19 pandemic on physical activity and sedentary behavior in children living in the U.S. BMC Public Health, 20(1), 1351. https://doi.org/10.1186/s12889-020-09429-3

Escalante-Izeta, E. I., Haua-Navarro, K., Moreno-Landa, L. I., \& Pérez-Lizaur, A. B. (2016). Variables nutricias asociadas con la ansiedad y la autopercepción corporal en niñas y niños mexicanos de acuerdo con la presencia de sobrepeso/obesidad. Salud Mental, 39(3), 157-163.

Ghosh, R., Dubey, M. J., Chatterjee, S., \& Dubey, S. (2020). Impact of COVID -19 on children: Special focus on the psychosocial aspect. Minerva Pediatrica, 72(3). https://doi.org/10.23736/S0026-4946.20.05887-9

Giménez-Dasí, M., Quintanilla, L., Lucas-Molina, B., \& Sarmento-Henrique, R. (2020). Six Weeks of Confinement: Psychological Effects on a Sample of Children in Early Childhood and Primary Education. Frontiers in Psychology, 11, 590463. https://doi.org/10.3389/fpsyg.2020.590463

Goodman, J. L., \& Borio, L. (2020). Finding Effective Treatments for COVID-19: Scientific Integrity and Public Confidence in a Time of Crisis. JAMA, 323(19), 1899. https://doi.org/10.1001/jama.2020.6434

Graber, K. M., Byrne, E. M., Goodacre, E. J., Kirby, N., Kulkarni, K., O’Farrelly, C., \& Ramchandani, P. G. (2021). A rapid review of the impact of quarantine and restricted environments on children's play and the role of play in children's health. Child: Care, Health and Development, 47(2), 143-153. https://doi.org/10.1111/cch.12832

Guizzo, B. S., Marcello, F. A., \& Müller, F. (2020). A reinvenção do cotidiano em tempos de pandemia. Educação e Pesquisa, 46. https://doi.org/10.1590/s1678-4634202046238077

Gutman, L. M., Joshi, H., \& Schoon, I. (2019). Developmental Trajectories of Conduct Problems and Cumulative Risk from Early Childhood to Adolescence. Journal of Youth and Adolescence, 48(2), 181-198. https://doi.org/10.1007/s10964-018-0971-x

Herrenkohl, T. I., Scott, D., Higgins, D. J., Klika, J. B., \& Lonne, B. (2021). How COVID-19 Is Placing Vulnerable Children at Risk and Why We Need a Different Approach to Child Welfare. Child Maltreatment, 26(1), 9-16. https://doi.org/10.1177/1077559520963916

Idoiaga, N., Berasategi, N., Eiguren, A., \& Picaza, M. (2020). Exploring Children's Social and Emotional Representations of the COVID-19 Pandemic. Frontiers in Psychology, 11. https://doi.org/10.3389/fpsyg.2020.01952

Instituto Nacional de Saúde da Mulher, da Criança e do Adolescente Fernandes Figueira (FIOCRUZ). (2020). COVID-19 e Saúde da Criança e do Adolescente. FIOCRUZ/IFF. http://www.iff.fiocruz.br/pdf/covid19_saude_crianca_adolescente.pdf

Jacob, C. M., Briana, D. D., Renzo, G. C. D., Modi, N., Bustreo, F., Conti, G., Malamitsi-Puchner, A., \& Hanson, M. (2020). Building resilient societies after COVID-19: The case for investing in maternal, neonatal, and child health. The Lancet Public Health, 5(11), e624-e627. https://doi.org/10.1016/S2468$2667(20) 30200-0$

Jiao, W. Y., Wang, L. N., Liu, J., Fang, S. F., Jiao, F. Y., Pettoello-Mantovani, M., \& Somekh, E. (2020). Behavioral and Emotional Disorders in Children during the COVID-19 Epidemic. The Journal of Pediatrics, 221, 264-266.e1. https://doi.org/10.1016/j.jpeds.2020.03.013

Lazzeroni, P., Bernardi, L., Pecora, F., Motta, M., Bianchi, L., Ruozi, M. B., Giacometti, A., Venezia, S., Dodi, I., \& Iovane, B. (2020). Diabetic ketoacidosis at type 1 diabetes onset: Indirect impact of COVID-19 pandemic. Acta Bio-Medica: Atenei Parmensis, 91(4), e2020193. https://doi.org/10.23750/abm.v91i4.10943

Linhares, M. B. M., \& Enumo, S. R. F. (2020). Reflexões baseadas na Psicologia sobre efeitos da pandemia COVID-19 no desenvolvimento infantil. Estudos de Psicologia (Campinas), 37. https://doi.org/10.1590/1982-0275202037e200089

Liu, Q., Zhou, Y., Xie, X., Xue, Q., Zhu, K., Wan, Z., Wu, H., Zhang, J., \& Song, R. (2021). The prevalence of behavioral problems among school-aged children in home quarantine during the COVID-19 pandemic in China. Journal of Affective Disorders, 279, 412-416. https://doi.org/10.1016/j.jad.2020.10.008

López, P. J. C., \& Prieto, F. J. G. (2020). Niveles de ansiedad según el estado de peso y la calidad de la dieta durante el estado de alarma en escolares de Primaria. Nutrición Clínica y Dietética Hospitalaria, 40(3), Article 3. https://doi.org/10.12873/403carrillo

Lynn, R. M., Avis, J. L., Lenton, S., Amin-Chowdhury, Z., \& Ladhani, S. N. (2021). Delayed access to care and late presentations in children during the COVID-19 pandemic: A snapshot survey of 4075 paediatricians in the UK and Ireland. Archives of Disease in Childhood, 106(2), e8-e8. https://doi.org/10.1136/archdischild-2020-319848

Maan, A. S., Kaur, G., Arora, R., Kaur, J., Devi, K. J., \& Singh, M. (2020). An Unusual Case of a Pediatric Nasal Septal Abscess with Life-Threatening Complications in COVID-19 Pandemic. Indian Journal of Otolaryngology and Head \& Neck Surgery, 1-4. https://doi.org/10.1007/s12070-020-02264-3

Manitto, A. M., Chiesa, A. M., Cunha, A. J. L. A., Abuchaim, B., Biderman, C., Kirschbaum, C., Santos, D. D., Santos, D. N., Mello, D. F., Louzada, F. M., Polanczyk, G.V., Brentani, H. P., Costa, J. S. M., Macedo, L., Fracolli, L. A., Scorzafave, L. G. D. S., Castro, M. C., Linhares, M. B. M., Campos, M. M., Souza, M. T. C. C., Menezes-Filho, N. A., Barros, R. P., Lerner, R., Rocha, R., \& Ponczek, V.P. (2020). Repercussões da Pandemia de COVID-19 no Desenvolvimento Infantil. Fundação Maria Cecilia Souto Vidigal. https://ncpi.org.br/wp-content/uploads/2020/05/Working-Paper-Repercussoes-da-pandemiano-desenvolvimento-infantil-3.pdf 
Mello, A. D. M., Marcon, S. S., Hulsmeyer, A. P. C. R., Cattai, G. B. P., Ayres, C. S. L. S., \& Santana, R. G. (2010). Prevalência de sobrepeso e obesidade em crianças de seis a dez anos de escolas municipais de área urbana. Revista Paulista de Pediatria, 28(1), 48-54. https://doi.org/10.1590/S010305822010000100009

Melnyk, B. M., \& Fineout-Overholt, E. (2019). Evidence-based practice in nursing and healthcare: A guide to best practice. (4nd ed). Wolters Kluwer.

Mendes, K. D. S., Silveira, R. C. C. P., \& Galvão, C. M. (2008). Revisão integrativa: método de pesquisa para a incorporação de evidências na saúde e na enfermagem. Texto contexto - enferm.;17,758-764.

Miranda, D. M., Athanasio, B. S., Oliveira, A. C. S., \& Simoes-e-Silva, A. C. (2020). How is COVID-19 pandemic impacting mental health of children and adolescents? International Journal of Disaster Risk Reduction, 51, 101845. https://doi.org/10.1016/j.ijdrr.2020.101845

Mondragon, N. I., Sancho, N. B., Santamaria, M. D., \& Munitis, A. E. (2020). Struggling to breathe: A qualitative study of children's wellbeing during lockdown in Spain. Psychology \& Health, 36(2), 179-194. https://doi.org/10.1080/08870446.2020.1804570

Moore, S. A., Faulkner, G., Rhodes, R. E., Brussoni, M., Chulak-Bozzer, T., Ferguson, L. J., Mitra, R., O’Reilly, N., Spence, J. C., Vanderloo, L. M., \& Tremblay, M. S. (2020). Impact of the COVID-19 virus outbreak on movement and play behaviours of Canadian children and youth: A national survey. International Journal of Behavioral Nutrition and Physical Activity, 17(1), 85. https://doi.org/10.1186/s12966-020-00987-8

Organização Mundial da Saúde (2008). Constituição da Organização Mundial da Saúde (OMS/WHO). http://www.direitoshumanos.usp.br/index.php/OMSOrganiza\%C3\%A7\%C3\%A3o-Mundial-da-Sa\%C3\%BAde/constituicao-da-organizacao-mundial-da-saude-omswho.html

Orgilés, M., Morales, A., Delvecchio, E., Mazzeschi, C., \& Espada, J. P. (2020). Immediate Psychological Effects of the COVID-19 Quarantine in Youth From Italy and Spain. Frontiers in Psychology, 11, 579038. https://doi.org/10.3389/fpsyg.2020.579038

Ornell, F., Schuch, J. B., Sordi, A. O., \& Kessler, F. H. P. (2020). "Pandemic fear" and COVID-19: Mental health burden and strategies. Brazilian Journal of Psychiatry, 42(3), 232-235. https://doi.org/10.1590/1516-4446-2020-0008

Ouzzani, M., Hammady, H., Fedorowicz, Z., \& Elmagarmid, A. (2016). Rayyan-A web and mobile app for systematic reviews. Systematic Reviews, 5(1), 210. https://doi.org/10.1186/s13643-016-0384-4.

Polit, D. F., \& Beck, C. T. (2018). Fundamentos de Pesquisa em Enfermagem-Avaliação de Evidências para a Prática da Enfermagem (9º ed). Artmed.

Pombo, A., Luz, C., Rodrigues, L. P., Ferreira, C., \& Cordovil, R. (2020). Correlates of children's physical activity during the COVID-19 confinement in Portugal. Public Health, 189, 14-19. https://doi.org/10.1016/j.puhe.2020.09.009

Qiu, J., Shen, B., Zhao, M., Wang, Z., Xie, B., \& Xu, Y. (2020). A nationwide survey of psychological distress among Chinese people in the COVID-19 epidemic: Implications and policy recommendations. General Psychiatry, 33(2), e100213. https://doi.org/10.1136/gpsych-2020-100213

Rodrigues, J. V. S., \& Lins, A. C. A. A. (2020). Possíveis impactos causados pela pandemia da COVID-19 na saúde mental de crianças e o papel dos pais neste cenário. Research, Society and Development, 9(8), e793986533. https://doi.org/10.33448/rsd-v9i8.6533

Ruiz-Eugenio, L., Roca-Campos, E., León-Jiménez, S., \& Ramis-Salas, M. (2020). Child Well-Being in Times of Confinement: The Impact of Dialogic Literary Gatherings Transferred to Homes. Frontiers in Psychology, 11. https://doi.org/10.3389/fpsyg.2020.567449

Saurabh, K., \& Ranjan, S. (2020). Compliance and Psychological Impact of Quarantine in Children and Adolescents due to Covid-19 Pandemic. Indian Journal of Pediatrics, 1-5. https://doi.org/10.1007/s12098-020-03347-3

Segre, M. \& Ferraz, F. C. (1997). O conceito de saúde. Rev. Saúde Pública, 31(5),538-42.

Sharpless, N. E. (2020). COVID-19 and cancer. Science, 368(6497), 1290-1290. https://doi.org/10.1126/science.abd3377

Silva, L. C. B., Novaes, C. R. M. N., Lima Júnior, R. A., Giudicelli, B. B., Cunha Júnior, A. T., Tenório, M. C. M., Martins, C. M. L., \& Tassitano, R. M. (2020). Sleep, sedentary behavior and physical activity: Changes on children's routine during the COVID-19. Revista Brasileira de Atividade Física \& Saúde, 25, 1-9. https://doi.org/10.12820/rbafs. $25 \mathrm{e} 0143$

Singh, N., Haokip, N., Rathore, P., Vig, S., \& Bhatnagar, S. (2020). Child in Institutional Quarantine - A Unique Challenge. Indian Journal of Palliative Care, 26(Suppl 1), S142-S144. https://doi.org/10.4103/IJPC.IJPC_162_20

Sociedade Brasileira de Pediatria. (2019). Manual de Orientação: \#Menos Telas \#Mais Saúde\#. SBP. https://www.sbp.com.br/fileadmin/user_upload/_22246c-ManOrient_-_MenosTelas_MaisSaude.pdf

Sonego, M., Llácer, A., Galán, I., \& Simón, F. (2013). The influence of parental education on child mental health in Spain. Quality of Life Research: An International Journal of Quality of Life Aspects of Treatment, Care \& Rehabilitation, 22(1), 203-211. https://doi.org/10.1007/s11136-012-0130-x

Spinelli, M., Lionetti, F., Pastore, M., \& Fasolo, M. (2020). Parents' Stress and Children's Psychological Problems in Families Facing the COVID-19 Outbreak in Italy. Frontiers in Psychology, 11, 1713. https://doi.org/10.3389/fpsyg.2020.01713

Stallard, P. (2002). Ansiedade: Terapia cognitivo-comportamental para crianças e jovens. Artmed.

Thomazini, M., \& Goulart, E. (2018). Relações familiares: A influência do virtual. Interacçôes, 48, 49-64.

Tíscar-González, V., Santiago-Garín, J., Moreno-Casbas, T., Zorrilla-Martínez, I., Nonide-Robles, M., \& Portuondo-Jiménez, J. (2020). Percepciones y vivencias de escolares de 7 a 8 años del País Vasco durante la alerta sanitaria COVID-19. Gaceta Sanitaria. https://doi.org/10.1016/j.gaceta.2020.11.006 
Research, Society and Development, v. 10, n. 7, e55510716727, 2021

(CC BY 4.0) | ISSN 2525-3409 | DOI: http://dx.doi.org/10.33448/rsd-v10i7.16727

Tso, W. W. Y., Wong, R. S., Tung, K. T. S., Rao, N., Fu, K. W., Yam, J. C. S., Chua, G. T., Chen, E. Y. H., Lee, T. M. C., Chan, S. K. W., Wong, W. H. S., Xiong, X., Chui, C. S., Li, X., Wong, K., Leung, C., Tsang, S. K. M., Chan, G. C. F., Tam, P. K. H., \& Lp, P. (2020). Vulnerability and resilience in children during the COVID-19 pandemic. European Child \& Adolescent Psychiatry. https://doi.org/10.1007/s00787-020-01680-8

Vigo, D., Patten, S., Pajer, K., Krausz, M., Taylor, S., Rush, B., Raviola, G., Saxena, S., Thornicroft, G., \& Yatham, L. N. (2020). Mental Health of Communities during the COVID-19 Pandemic. Canadian Journal of Psychiatry. Revue Canadienne De Psychiatrie, 65(10), 681-687. https://doi.org/10.1177/0706743720926676

Wang, G., Zhang, Y., Zhao, J., Zhang, J., \& Jiang, F. (2020). Mitigate the effects of home confinement on children during the COVID-19 outbreak. The Lancet, 395(10228), 945-947. https://doi.org/10.1016/S0140-6736(20)30547-X

Williams, R., Jenkins, D. A., Ashcroft, D. M., Brown, B., Campbell, S., Carr, M. J., Cheraghi-sohi, S., Kapur, N., Thomas, O., Webb, R. T., \& Peek, N. (2020). Diagnosis of physical and mental health conditions in primary care during the COVID-19 pandemic: a retrospective cohort study. The Lancet Public Health, 5(10), e543-e550. https://doi.org/10.1016/S2468-2667(20)30201-2

World Health Organization. (2020). Mental health and psychosocial considerations during the COVID-19 outbreak, 18 March 2020 (WHO/2019nCoV/MentalHealth/2020.1). WHO. https://apps.who.int/iris/handle/10665/331490

World Health Organization (WHO). (2020, março 11). WHO Director-General's opening remarks at the media briefing on COVID-19-11 March 2020 [Oficial]. https://www.who.int/director-general/speeches/detail/who-director-general-s-opening-remarks-at-the-media-briefing-on-covid-19---11-march-2020

Xue, Q., Xie, X., Liu, Q., Zhou, Y., Zhu, K., Wu, H., Wan, Z., Feng, Y., Meng, H., Zhang, J., Zuo, P., \& Song, R. (2021). Knowledge, attitudes, and practices towards COVID-19 among primary school students in Hubei Province, China. Children and Youth Services Review, $120,105735$. https://doi.org/10.1016/j.childyouth.2020.105735

Yeasmin, S., Banik, R., Hossain, S., Hossain, M. N., Mahumud, R., Salma, N., \& Hossain, M. M. (2020). Impact of COVID-19 pandemic on the mental health of children in Bangladesh: A cross-sectional study. Children and Youth Services Review, 117, 105277. https://doi.org/10.1016/j.childyouth.2020.105277

Yehuda, R., Halligan, S. L., \& Grossman, R. (2001). Childhood trauma and risk for PTSD: Relationship to intergenerational effects of trauma, parental PTSD, and cortisol excretion. Development and Psychopathology, 13(3), 733-753. https://doi.org/10.1017/s0954579401003170

Zhang, J., Shuai, L., Yu, H., Wang, Z., Qiu, M., Lu, L., Cao, X., Xia, W., Wang, Y., \& Chen, R. (2020). Acute stress, behavioural symptoms and mood states among school-age children with attention-deficit/hyperactive disorder during the COVID-19 outbreak. Asian Journal of Psychiatry, 51, 102077. https://doi.org/10.1016/j.ajp.2020.102077 